\title{
Mindfulness: An Introduction ${ }^{1}$
}

\author{
Parth Naik, Victor Harris, and Larry Forthun²
}

Take a minute to stop everything you are doing and focus on your breath. Can you still your mind?

Sounds simple, right? Chances are if you are like most Americans you found it challenging to calm your mind for more than a few seconds. However, research suggests this skill may be vital to deal with one of the biggest public health issues facing America today: stress. So how can you learn to be calmer, more centered, and less stressed? In recent years, psychologists and physicians have turned to a practice called mindfulness with promising results.

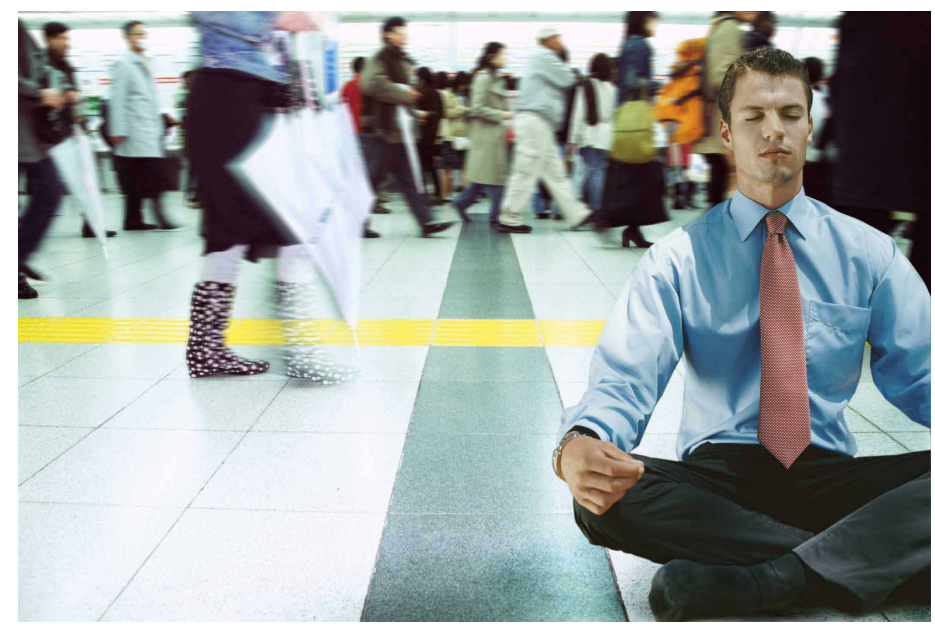

Figure 1. Credits: Rupert King (Digital Vision)

\section{What Is Mindfulness?}

"Mindfulness means paying attention in a particular way; on purpose, in the present moment, and nonjudgmentally." -

$$
\text { Dr. Jon Kabat-Zinn (1991) }
$$

Mindfulness is best thought of as a way of being rather than an activity in and of itself. Almost any activity can be carried out with mindful awareness. Originally associated with Buddhist psychology, the term "mindfulness" comes from the Sanskrit word "Smrti", which literally translates to "that which is remembered" (Williams, Leumann, \& Cappeller, 2004). From this, we can understand mindfulness as remembering to pay attention to our present moment experience (Shapiro \& Carlson, 2009; Black, 2011).

Mindful awareness has three key features:

- Purpose - Mindfulness involves intentionally and purposefully directing your attention rather than letting it wander.

- Presence - Mindfulness involves being fully engaged with and attentive to the present moment. Thoughts about the past and future that arise are recognized simply as thoughts occurring in the present.

- Acceptance - Mindfulness involves being nonjudgmental toward whatever arises in the moment. This means that sensations, thoughts, and emotions are not judged as good or bad, pleasant or unpleasant; they are simply noticed as "happening," and observed until they eventually pass.

1. This document is FCS2335, one of a series of the Department of Family, Youth and Community Sciences, UF/IFAS Extension. Original publication date: September 2013. Please visit the EDIS website at http://edis.ifas.ufl.edu.

2. Parth Naik, undergraduate student, Department of Family, Youth and Community Sciences; Victor Harris, assistant professor and Extension specialist, Department of Family, Youth and Community Sciences; and Larry Forthun, associate professor and Extension specialist, Department of Family, Youth and Community Sciences; UF/IFAS Extension, Gainesville, FL 32611. 
Research into mindfulness and its applications has increased exponentially over the past two decades. Although originally a Buddhist concept, mindfulness is now understood to be an inherent quality of consciousness that can be measured empirically and scientifically (Kohls, Sauer, \& Walach, 2009; Black, 2010). It is also understood that mindfulness requires no religious, ethical, spiritual, or ideological commitments to practice (Walach et al., 2007).

The scientific interest in mindfulness has been largely credited to the work of Dr. Jon Kabat-Zinn, founder of the University of Massachusetts Medical School Stress Reduction Clinic. Kabat-Zinn, an MIT-trained molecular biologist, began researching mind-body medicine in the mid-1970s, focusing on the clinical application of mindfulness meditation for individuals afflicted with chronic pain and stress-related illnesses (Kabat-Zinn, 2005; Kabat-Zinn, 1991). From this research, he developed the MindfulnessBased Stress Reduction (MBSR) curriculum, an eight-week training course that has been successfully used with a wide audience, from cancer patients to those suffering from depression to highly stressed business executives (Grossman, Niemann, Schmidt, \& Walach, 2004; Walach et al., 2007).

More than 200 major medical centers across the United States now implement MBSR, and many adaptations of mindfulness-based therapies have followed, including Mindfulness-Based Cognitive Therapy (Teasdale et al., 2000).

\section{Benefits of Mindfulness}

Mindfulness is a mind-body practice that has been found to benefit both psychological and physical health. The primary psychological change that occurs during mindfulness practice is an increased awareness of thoughts, feelings, and sensations in the present moment. Over time mindfulness practice can help you to become aware of the space between noticing experiences and reacting to them by letting you slow down and observe the processes of your mind (Black, 2010). The ultimate goal of mindfulness practice is for you to take advantage of this space so you can make more intentional decisions - to wake up from living life on autopilot, based on unproductive habits of mind (Black, 2010; Walach et al., 2007).

It is easy to see how mindfulness could be beneficial in dealing with stress or other difficult emotions. For example, we have all been in situations where we became angry or stressed and said or did things we didn't mean. In these moments, we may have felt we had no control over our

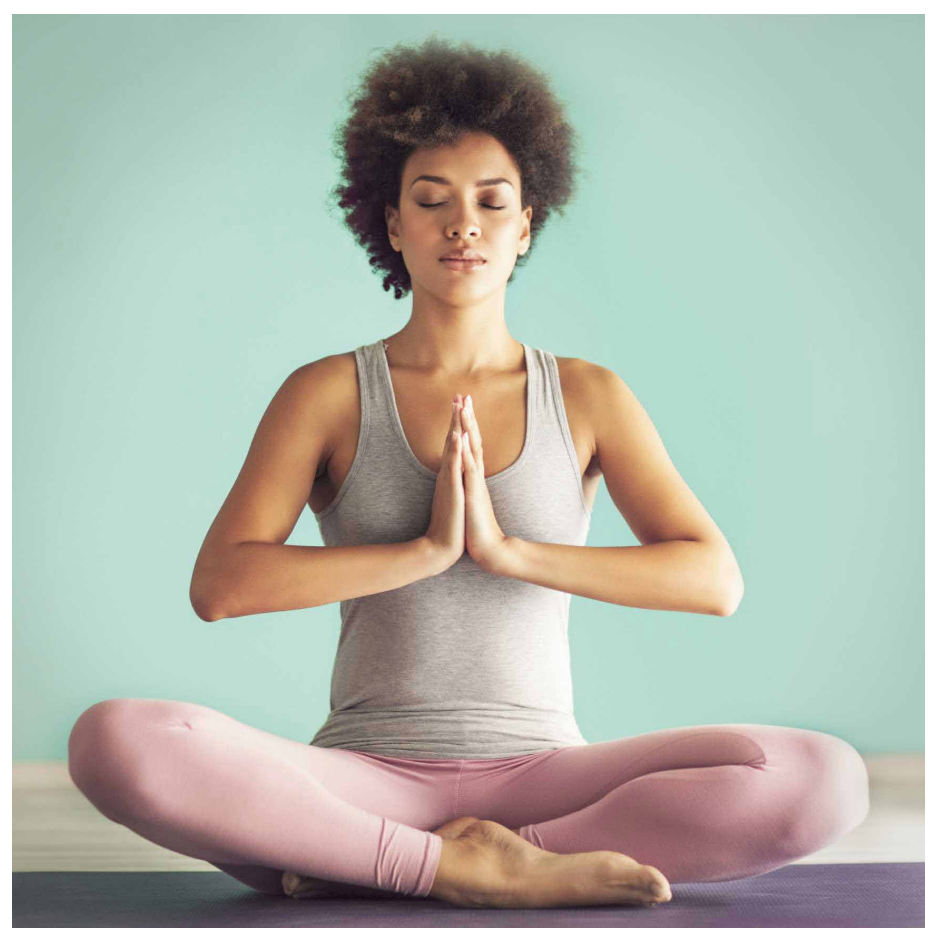

Figure 2. Credits: iStockphoto

words or actions-as if we were reacting to situations without thinking.

If you experience a moment like this, mindfulness can help in several ways. First, being mindful can help you become more aware of your emotions before they escalate and control you. Instead of recognizing your anger only after you lash out at someone, you can catch your anger when it is still mild and take steps to diffuse it. Furthermore, mindfulness can help you look at your thoughts and emotions with more objectivity. Instead of letting minor events trigger negative thinking, mindfulness lets you take a step back to recognize you are feeling stressed or anxious and this anxiety may be influencing your thoughts.

So how can mindfulness help you respond to your emotions after you have recognized them? Problems with regulating emotions fall into two categories, either repression or excessive reactivity. Instead of ignoring emotions completely or acting on every emotion impulsively, mindfulness provides a third option: "being with" emotions. By holding your emotions in mindful awareness, you can separate your raw emotions and the accompanying sensations from the thoughts you have about them. This would be the difference between thinking about all the reasons you are upset and simply recognizing you are upset. Being with your emotions in this way lets you observe your emotions closely until they naturally pass, and it also lets you intentionally make decisions about how to respond to the information your emotions provide. 
According to the American Psychological Association, some empirically supported benefits of mindfulness include the following (Davis \& Hayes, 2011):

\section{Psychological Benefits}

- Increased awareness of one's mind

- Significantly reduced stress, anxiety, and negative emotions

- Increased control over ruminative thinking (a major cause and symptom of depression and anxiety)

- Increased mental flexibility and focus

- More working memory

- Decreased distracting thoughts

- Decreased emotional reactivity

- Increased capacity for intentional, responsive behaviors

- Increased empathy, compassion, and conscientiousness of other's emotions

\section{Physiological Benefits}

- Enhanced immune system functioning

- Increased brain density and neural integration in areas responsible for positive emotions, self-regulation, and long-term planning

- Lowered blood pressure

- Lowered levels of blood cortisol (a major stress hormone)

- Greater resistance to stress-related illnesses such as heart disease

\section{Spiritual Benefits}

- Increased self-insight and self-acceptance

- Increased acceptance of others

- Increased compassion and empathy

- Increased sense of morality, intuition, and courage to change

- Increased control over automatic behaviors

- Increased self-discipline

\section{How Can You Start Practicing}

\section{Mindfulness?}

"Mindfulness is a habit, it's something the more one does, the more likely one is to be in that mode with less and less effort ... it's a skill that can be learned. It's accessing something we already have. Mindfulness isn't difficult. What's difficult is to remember to be Mindful." -

John Teasdale, co-originator of MBCT (Rock, 2009)

With mindfulness practice, learning how to be mindful is only the tip of the iceberg. The bulk of this practice is about familiarizing yourself with what it feels like to be mindful, and getting better at "remembering" to maintain mindful awareness. This means that almost any activity can be turned into a mindfulness practice if it involves the following basic components:

\section{Direct involvement of one of your five senses - Focus-} ing on one of your senses grounds you in the present moment. It also provides you with the opportunity to separate the sensory experience from the thoughts you are having about it.

2. An "anchor" - The anchor serves as the object of attention during mindfulness practice. For example, if you are being mindful of your breath, you should try to maintain a continual awareness of the physical sensation of your breath entering and leaving your body. This could mean feeling the air entering and exiting your nostrils, or even the sensation of your lungs expanding and contracting. The exact sensation doesn't matter as long as you can keep focused on it. Some other common examples of anchors are the sound of a bell, or the taste and texture of food. The range of possibilities is practically limitless, so feel free to experiment.

3. Returning to the anchor - This is where the power of mindfulness practice comes from. Chances are you will only be able to remain focused on your anchor for a few moments before becoming distracted. This is $O K$ and to be expected. When you realize you have lost focus, gently refocus your attention on the anchor.

With time and practice, your mind will begin to settle into calmness and you will find yourself able to focus for longer periods. While at first you may only notice yourself drifting from your anchor long after you start daydreaming, eventually you will start to notice distractions (such as thoughts or sensations) as they arise. Instead of being lured away from your anchor by these distractions, it will be easier to simply notice them and let them pass. A helpful metaphor to keep 
in mind is that your distractions are like clouds passing in the sky-notice them without judgment and then let them pass without a trace.

Experiment with creating your own mindfulness practices throughout the day. Being mindful of the sensation on the soles of your feet as you walk to your car or the taste and texture of your morning coffee can transform routine moments into deeply satisfying practices. However, having a ritualized and structured practice can be beneficial. Below are instructions for two common mindfulness practices.

\section{Mindful Breathing (Formal Seated Breath Meditation)}

1. Posture - Assume a comfortable upright but relaxed sitting posture. There is no requirement to sit on the floor, and sitting in a chair is perfectly acceptable. The key is to choose a posture that lets you be comfortable and alert. You can choose to keep your eyes open, but if you are a beginner, it may be easier to keep your eyes closed to avoid distractions. If you choose to keep your eyes open, let your gaze rest softly a few feet in front of you on the floor without focusing on a particular object.

2. Getting grounded - Take a few moments to notice any tension you may be holding in your body. Relax your face and jaw, and let your shoulders relax. Feel the weight of your body resting on the ground or in your chair.

3. Notice your breath - Once you begin to feel grounded in your body, try to notice the sensation of your breath. Some sensations you could focus on include the air as it enters and leaves your nose, the expanding and contracting of your lungs, or the sound of the air in your throat. If you have difficulty feeling your breath, it may help to place one hand on your belly so that you can feel it rising and falling as you breathe.

4. Staying with your breath - Now that you have settled your attention on your breath, try to keep your attention on it as long as you can. Remember to stay relaxed with both your posture and attention. If you feel yourself becoming rigid or dozing off, feel free to reset your posture and release any tension you feel.

If you notice that your attention has drifted away from your breath, gently guide it back to feeling your breath in the present moment. If you notice thoughts arising, try not to judge them or yourself! Simply acknowledge their presence and let them pass. Always remember that the most important part of this practice is not how long you can stay focused, but gently returning your attention to your breath when you lose focus.

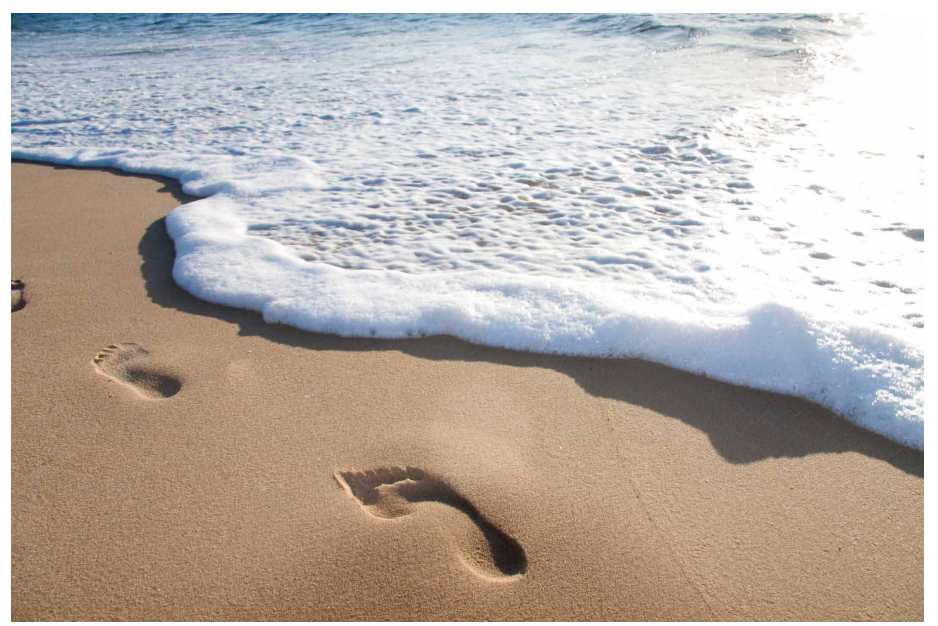

Figure 3. Credits: iStockphoto

\section{Mindful Walking}

1. Posture - Stand straight and alert, but not rigidly so. Evenly distribute your weight between your feet. You can relax your arms by your sides or hold them behind your back if they are distracting. Take a moment to feel the weight of your body supported by the ground. Soften and drop your gaze slightly if this helps you focus.

\section{Choosing your path - If this is your first time trying} mindful walking, you may feel more comfortable if you choose a short path (no longer than 100 feet) and walk back and forth on that path. As you become comfortable with the practice, feel free to choose a more elaborate path or even try walking mindfully as you go about your day.

3. Walking - As you take your first steps, focus your attention on the sensation of your weight shifting on the soles of your feet. If you are barefoot, try noticing the textures of the ground. Maintain a steady rhythm as you walk; it may also be useful to walk a bit slower than you usually would.

4. Staying with the steps - As you fall into rhythm, keep your attention focused on the sensations coming from the soles of your feet. If you catch yourself drifting off, gently guide your attention back to your feet. Once again, the most important aspect of this practice is not how long you stay focused, but rather noticing your mind wandering and then refocusing it. 


\section{Common Problems and Tips for Dealing with Them}

There's a saying that goes "those who don't have time to meditate need to meditate the most!" Finding the time to maintain a "mindfulness practice" can be one of many difficulties in today's fast-paced world, but keep in mind that even ten minutes of practice a day adds up! Here are some other common problems and tips to deal with them:

- "I can't stop thinking." - The key to dealing with thoughts while practicing mindfulness, as paradoxical as it seems, is not to resist them. Instead, the idea is to notice thoughts without identifying with them, as if observing your own thoughts from a distance while resting in the still space of your mind.

- "I feel too restless to be mindful" - It's normal to feel restless when trying to sit still, especially when most of your time is spent rushing around in an overstimulating world! Often you may feel the need to move around and get things done while trying to practice mindfulness. The best way to deal with this is to stick with the practice until your body and mind have had time to slow down. When they slow down, the restlessness will naturally dissipate.

- "I feel too tired to be mindful" - Slowing down and checking in with yourself can make you realize how tired you really are. If you consistently feel tired while trying to practice mindfulness, you may want to check your sleeping habits. However, if you suspect your drowsiness is coming from boredom, you may want to try a more physically active mindfulness practice such as mindful walking.

\section{- Dealing with uncomfortable emotions that arise - It is} common for emotions that have been ignored throughout the day to arise as you shift your focus inward. Sometimes these emotions can be uncomfortable or unpleasant, and you may feel the urge to resist them. Instead, if you allow these feelings to arise without judging them or following the stories your mind creates about these emotions, you'll find that your emotions will naturally pass. One way to do this is to focus on observing the physical sensations that accompany your emotions, such as the tightness in your chest that anxiety may produce. Of course, if these emotions are very powerful or especially disturbing, it may be helpful to seek support from a professional counselor.

\section{Conclusions}

Learning to be mindful is a powerful skill that can help you face the stresses of day-to-day life and improve both your

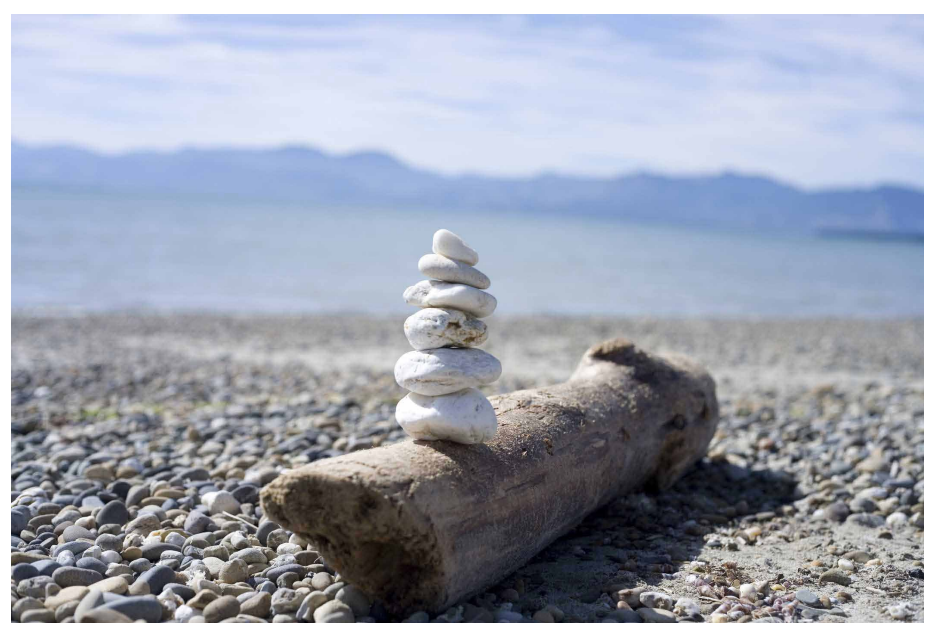

Figure 4. Credits: iStockphoto

psychological and physical health. Because you don't need any equipment to practice mindfulness, you can practice it discreetly anywhere, at any time. Although mindfulness may be easy to learn, the difficulty comes with remembering to be mindful throughout the day. On the following page there is a chart you can use to help track how mindful you are being throughout the week (Table 1). You may want to keep this chart with you or put it somewhere you will see it every day, such as on the refrigerator door. Feel free to place a "+" next to each mindful behavior you practice throughout the day.

So, next time you are feeling anxious, stressed, or uncomfortable, take a moment to check in with yourself and be more mindful!

\section{References}

Baer, R. A., Smith, G. T., Hopkins, J., Krietemeyer, J., \& Toney, L. (2006). Using self-report assessment methods to explore facets of mindfulness. Assessment, 13, 27-45.

Black, D. S. (2011). A brief definition of mindfulness. Mindfulness Research Guide. Retrieved from http://www. mindfulexperience.org

Black, D. S. (2010). A 40-year publishing history of mindfulness. Mindfulness Research Monthly, 1(5). Retrieved from http://www.mindfulexperience.org

Davis, D., \& Hayes, J. (2011). What are the benefits of mindfulness? A practice review of psychotherapy-related research. Psychotherapy, 48(2), 198-208. doi:10.1037/ a0022062

Grossman, P., Neimann, L., Schmidt, S., \& Walach, H. (2004). Mindfulness-based stress reduction and health 
benefits: A meta-analysis. Journal of Psychosomatic Research, 57, 35-43. doi:10.1016/S0022-3999(03)00573-7

Kabat-Zinn, J. (2005). Wherever you go, there you are: Mindfulness meditation in everyday life. New York, NY: Hyperion.

Kabat-Zinn, J. (1991). Full catastrophe living: Using the wisdom of your body and mind to face stress, pain, and illness. New York: Delacorte

Kohls, N., Sauer, S., \& Walach, H. (2009). Facets of mindfulness - Results of an online study investigating the Freiburg mindfulness inventory. Personality and Individual Differences, 46, 224-230. doi:10.1016/j.paid.2008.10.009

Rock, D. (2009, October 11). The neuroscience of mindfulness. Psychology Today. Retrieved from http:// www.psychologytoday.com/blog/your-brain-work/200910/ the-neuroscience-mindfulness

Shapiro, S. L. \& Carlson, L. E. (2009). The art and science of mindfulness: Integrating mindfulness into psychology and the helping professions. Washington, DC: APA
Teasdale, J., Williams, J., Soulsby, J., Segal, Z., Ridgeway, V., \& Lau, M. (2000). Prevention of relapse/recurrence in major depression by mindfulness-based cognitive therapy. Journal of Consulting and Clinical Psychology, 68(4), 615-623. doi:10.1037//0022-006X.68.4.615

Walach, H., Nord, E., Zier, C., Dietz-Waschowski, B., Kersig, S., \& Schupbach, H. (2007). Mindfulness-based stress reduction as a method for personnel development: A pilot evaluation. International Journal of Stress Management, 14(2), 188-198. doi:10.1037/1072-5245.14.2.188

Williams, M., Leumann, E., \& Cappeller, C. (2004). Etymologically and philologically arranged with special reference to cognate Indo-European languages. New Delhi: Bharatiya Granth Niketan.

Table 1.

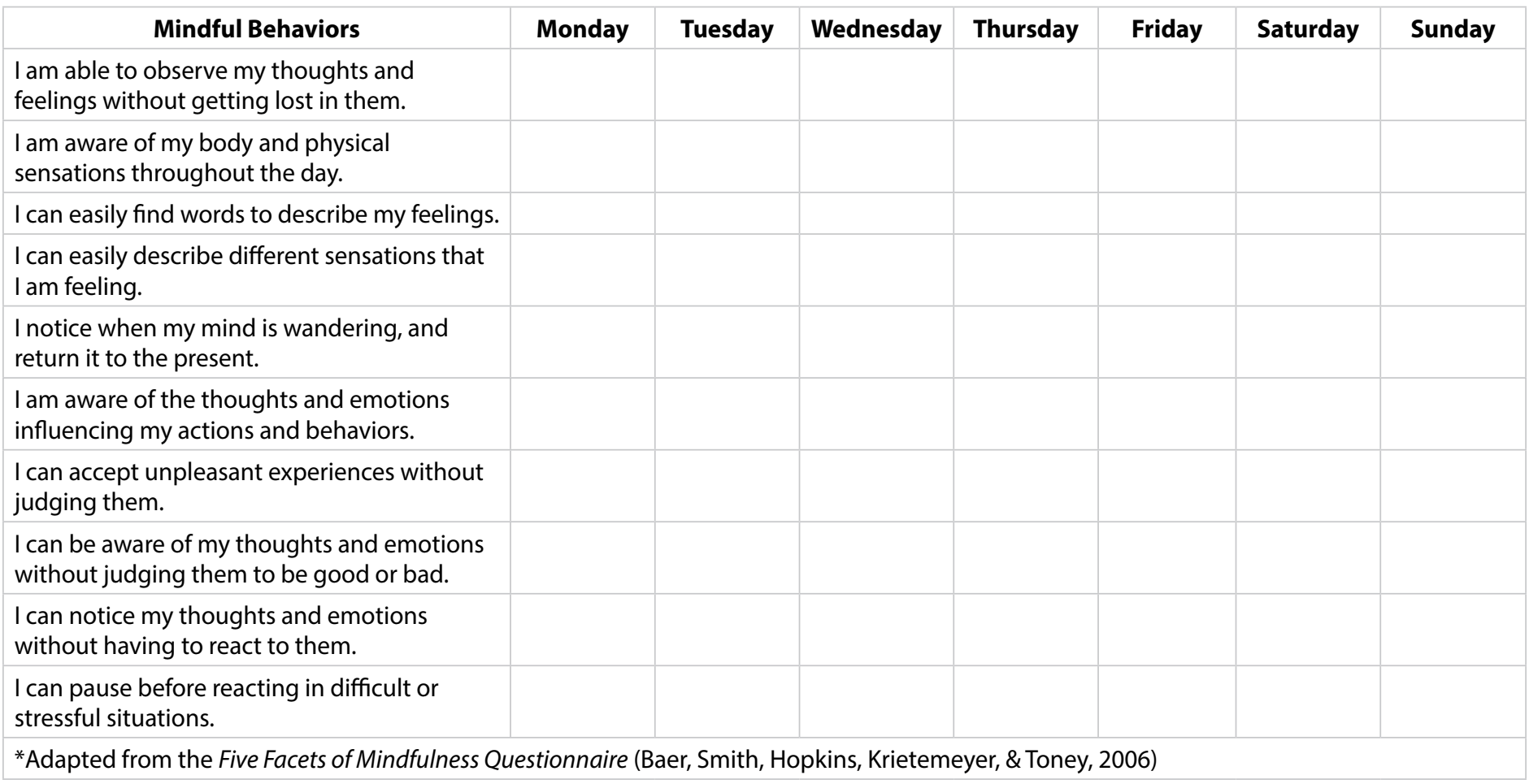

